\title{
Cognitive Bias in Decision Making According to Change of Tax Policy: An Exploratory Study
}

\author{
Seong-hoon Jeong ${ }^{1}$, In-ho Choi ${ }^{2}$ \\ ${ }^{1}$ Department of Economics \& International Trade, Catholic University of Daegu, \\ Daegu 384-30, South Korea. \\ ${ }^{2}$ Department of Real Estate, Namseoul University, 91 Daehak-ro, Seonghwan- \\ eup, Cheonan-si, Chungnam. 331-707South Korea. \\ ${ }^{1}$ James1101@cu.ac.kr, ${ }^{2}$ landchoi@nsu.ac.kr(Corresponding author)
}

\begin{abstract}
The purpose of this study is to analyze the cognitive bias in decision making of real estate investors according to change of tax policy. This study was based on the return rate of the investors. However, changing of tax policy is influenced not only by the return rate, but also influenced by the investment psychology of real estate investors. This study investigated the response of investment psychology according to tax policy and established the DGR-DLR model which is a frequency model used for the potential profit and the loss rate. It has investigated the real estate investor's cognitive bias and the influence of change of tax policy using 2,245 copies of residence register to solve the data collection problem. The results of the study were rejected in the first and second increase of transfer income tax and in the second increase of acquisition tax.
\end{abstract}

Keywords: Acquisition tax, transfer income tax, potential rate of profit model, gain of a real estate model, loss of real estate model, tax policy, DGR-DLR model.

\section{Introduction}

The tax system can be categorized into two parts: trading tax (acquisition tax and registration tax) and holing tax (property tax and comprehensive real estate holing tax). The two types of taxes are commonly discussed in tax studies. The acquisition tax is mainly discussed as a trading tax. Han and Yoo (2011) examined how the trading volume of the house change after the change of the trading tax rate that has been formed. In case of the tax rate related to the trading, market changes were visible because it was used as a governmental policy for the real estate market. The result of 
the study shows that, although trading rate is decreased, the house trading volume increases were in significant. This means that the decrease in trading tax rate does minimal effect to activate the depressed house trading. Park and Rim (2012) researched the effect of acquisition tax reduction on the activation of house market to figure out its effectiveness. In contrast to the other studies, Park and Rim (2012) investigated the policy of acquisition tax reduction with a two-part classification: a chronic acquisition tax reduction policy, which is the policy done from 2006 and; a temporary acquisition tax reduction policy, which is the policy with a limited period done from March 2011 to the end of the same year. The result of the study shows that both of classifications have few effect on the real estate market, which is same with the research of Han and Yu (2011).

The same conclusion was stated in Rim's study (2013) that analyzed the housing demand change after the acquisition tax reduction. A regression analysis was used to analyze the change of demand after the reduction of acquisition tax rate using the selling price, the stock price and the income, and so on. In conclusion, Rim's study agrees with the studies conducted by Han and Yu (2011) and Park and Rim (2012) that the reduction of acquisition tax and housing trade rate is insignificant. It suggests the tax rate reduction does not affect the real estate market vitalization.

On the other hand, there is a different result in the study of holding tax. Lee and Kim (2008) analyzed the relation between property tax and cost of the apartment using VAR model based on the national housing costs survey researched from 1989 to 2005 by Kookmin Bank. In this research, the effect of property tax volatility has a significant positive effect on the selling price of apartment and the residence price. It could be interpreted that the increase of the tax rate on property increases the price influencing the apartment price.

Jung and park (2009) did an empirical research on the vitalization of real estate selling, conducting the comprehensive real estate holding tax and the heavy tax policy of capital gains tax for the multiple-house owners. The comprehensive real estate holding tax and heavy tax policy of capital gains tax for the multiple-house owner would increase the burdens for speculation holders. Therefore the speculation holders consider various ways to reduce the holding tax such as the comprehensive real estate holding tax and heavy tax policy of capital gains tax for multiple-house owner.

It implies that they sold the houses because it is much easier that way to increase the trade volume.

There are differences among the studies of Lee and Kim (2008), Jung and Park (2009), Han and Yu (2011), Park and Rim (2012) and Rim (2013). However, the differences are caused by the different purpose of taxation. At first, Jung and Park (2009) adjusted the real estate tax policy to control the speculation. Meanwhile, Han and Yu (2011) and Rim (2013) adjusted the real estate tax system to give profit to the investors for vitalization the trade. None of the studies have a refund step, which means that they did not considered the concept of compensation. They analyzed real 
estate tax policy as a concept of loss. In the mechanism of the prospect theory, investors would response more on the loss that is predicted, which is the same with the study of Jung and Park (2009).

\section{Study Objective.}

The purpose of this study is to find out the cognitive bias of real estate investors using the maximized potential rate of profit model, the maximized potential rate of loss model, the gain of a real estate model and the loss of real estate model. I will also verify the effect of tax policy on investor's cognitive bias. Recent anomaly which frequently happens in the stock market also occurs in the real estate market.

The anomaly is hard to be explained with the main current theory - the efficiency market theory (Thaler, 1999). Researchers of behavioral finance and behavioral tax suggest that the anomaly comes from the cognitive bias of investors. This study investigates the cognitive bias of investors using the disposition effect depending on the change of tax policy.

\section{Study Method}

Changing of tax policy is influenced not only by the return rate, but also influenced by the investment psychology of real estate investors (Walsh, 2013). With point of view, this study investigated the response of investment psychology according to tax policy and established the models below.

\subsection{Frequency of profit and loss compare models Since 1967, KDA has}

The main purpose of this study is to verify the investment psychology response of investors. It can be verified by figuring out the most active timing for the investment psychology response. Most studies focused on a selling time estimates that the investment psychology response is the most active when they sell stocks or real estate (Kahle et al., 2004). Therefore, this study compares the frequency of gain and loss before and after the changing of tax policy. The formula of this models can be expressed like (1) and (2).

If

$$
\left(P_{t}-P_{b t}\right)>0 \text { then } G R
$$

else if

$$
\left(P_{t}-P_{b t}\right)=<0 \text { then } L R
$$

$G R$ : Gain of Real Estate, $L R$ : Loss of Real Estate, $P_{b t}$ : Price of Time on buy, $P_{t}$ : Price of Time to sell, GR, $L R$ is distinguished by the changing time of each of tax policies.

$$
\begin{aligned}
& \mathrm{DGR}_{t}=G R_{t}-G R_{t-1} \\
& D L R_{t}=L R_{t}-L R_{t-1} \\
& \sum_{t=1}^{T} D G R_{t}
\end{aligned}
$$




$$
\sum_{t=1}^{T} D L R_{t}
$$

$\sum_{t=1}^{T} D G R_{t}$ : Sum of Frequency of Gain of Real Estate, $\sum_{t=1}^{T} D L R_{t}$ : Sum of Frequency of Loss of Real Estate, $D G R_{t}$ : Frequency of Gain of Real Estate, DLR: Frequency of Loss of Real Estate.

\subsection{The Example Of GR and LR Model}

Meanwhile, realized loss can affect a lot in the bear market. Therefore, when comparing the model of gain and loss frequency, bull market and bear market should be studied separately.

Table 1 shows an example of the model. When assuming that a reduction of the acquisition tax has been carried out February 1, 2010, then the frequency of profit and loss can be calculated as follows: First of all, buyer A and E are included in frequency of realized gain before the implement date $\left(\mathrm{GR}_{(\mathrm{t}-1)}\right)$, which is 2 . In case of the frequency of realizing loss $\left(\mathrm{LR}_{\mathrm{t}-1}\right)$, where buyers $\mathrm{B}$ and $\mathrm{F}$ belong. It is 2 . At this time, buyer F's purchase price and sold price are same.

This is estimated as a loss because this case was affected by various costs like taxes and fees. Next, after the implementing date, buyer $\mathrm{C}$ and $\mathrm{G}$ are included in the frequency of realized gain and this value (GRt), which is 2. At the same time, buyer $\mathrm{D}$ is included in the frequency of realized losses (LRt), which is 1 . At this time, it calculates DGRt and DLRt to study the response of the investors after the reduction of the acquisition tax.

Table 1: Example of gain and loss frequency compare models table

\begin{tabular}{|c|c|c|c|c|c|}
\hline Buyer & Purchase date & Sold date & $\begin{array}{c}\text { Purchase } \\
\text { price }\end{array}$ & Sold price & Gain/Loss \\
\hline A & $2009-03-01$ & $2010-01-04$ & 20,000 & 21,000 & Gain \\
\hline B & $2009-02-05$ & $2010-01-02$ & 22,000 & 19,000 & Loss \\
\hline C & $2009-05-02$ & $2010-02-02$ & 6,000 & 12,000 & Gain \\
\hline D & $2009-07-01$ & $2010-02-20$ & 10,000 & 9,000 & Loss \\
\hline E & $2007-06-02$ & $2010-01-04$ & 21,000 & 25,000 & Gain \\
\hline F & $2006-09-29$ & $2010-01-21$ & 25,000 & 25,000 & Loss \\
\hline G & $2008-08-09$ & $2010-02-06$ & 7,000 & 10,000 & Gain \\
\hline
\end{tabular}

$\mathrm{GR}_{\mathrm{t}}$ shows 0, which is $\mathrm{GR}_{\mathrm{t}}(2)-\mathrm{GR}_{\mathrm{t}-1}(2)$. DLR $\mathrm{t}$ shows - 1 , which is $\mathrm{LR}_{\mathrm{t}}(1)-\mathrm{LR}_{\mathrm{t}}$ ${ }_{1}(2)$. That means that it is considered that the frequency of realized loss has decreased once at the reduction of acquisition tax.

\subsection{PRMR and LRMR Model}

Frequency of profit and loss compare models, which are previously described, are possible solutions to analyze investment performance sorted by the frequency 
(Talpsepp, 2011). Although investors could get more profit, nothing shows whether the investors realized profit quickly or investor showed the appropriate reaction to loss (Collins et al., 2000). Therefore this study analyzes the performance of the investor's decision using PRMR and LRMR model, where PRMR is profit real estate maximized potential rate of profit (Zhonglan et al., 2008), while LRMR is loss real estate maximized potential rate of loss (Elffers et al., 1992). This model analyzes the added potential profit or loss when an investor does not realize profit or loss (Engelhardt and quot, 2003). Before using this model, this paper grasped the maximized potential profit and the maximized potential loss. Although in the stock market, it is easy to find some stock's maximized potential profit or maximized potential loss because of the daily stock price data existing in the market. In case of real estate market, it is hard to see maximized potential profit or maximized potential loss. Since this model needs the price of real estate to work, this paper uses the land price of the area as a proxy (Jeong and Choi, 2019).

$$
\begin{aligned}
& \mathrm{PRMR}=\sum_{t=1}^{n} \frac{M P R P}{R R P+M P R P} \\
& \mathrm{LRMR}=\sum_{t=1}^{n} \frac{M P R L}{R R L+M P R L}
\end{aligned}
$$

PRMR: Profit Real Estate Maximized Potential Rate of Profit

LRMR: Loss Real Estate Maximized Potential Rate of Loss

MPRP: Maximized Potential Rate of Profit in Real Estate Price Index

MPRL: Maximized Potential Rate of Loss in Real Estate Price Index

RRP: Realized Rate of Profit, RRL: Realized Rate of Loss

$$
\mathrm{H}=\frac{12}{n(n+1)} \sum \frac{T_{i}^{2}}{n_{i}}-3(n+1)
$$

$\mathrm{T}_{\mathrm{i}}$ : Rank sum of $\mathrm{i}$ group, $\mathrm{n}_{\mathrm{i}}$ : Number of group.

This method verifies the null hypothesis, "samples are same", as rejected or not, through measuring approximate significance probability using the calculated chi squared from statistical value $\mathrm{H}$ (Odean, 2003).

\section{Results : Empirical Analysis}

\subsection{Analysis of Frequency of Loss and Profit for Increasing Tax Rate}

The result of analysis revealed that the realized gain trades before January 1, 2011, the first tax increase implementation, were 63 cases. On the other hand, 67 cases of gain realizing trade occurred after the increase.

Therefore, DGR is calculated at 4 . In addition, the number of the realized loss trade were 9 same as before and after the increase, in which DGR is calculated at 0.

DGR is calculated at 0 . For the second tax increase implementation as of January 1 , 2012, DGR is lower than 0, and DLR is calculated at -2. It is suggested that investors sell more than before the implementation.

For the second acquisition tax increase period, DGR is 1 and the DLR is -2 . It 
means that profit investors sell more than after the implementation. However, the loss were sold by the investors before the implementation. For the period of third acquisition increase implementation, both DGR and DLR are negative numbers.

Table 2: The DGR-DLR analysis when tax increased

\begin{tabular}{|c|c|c|c|c|}
\hline $\begin{array}{l}\text { Implementation } \\
\text { of tax increase }\end{array}$ & $\begin{array}{c}\text { Separate Gain } \\
\text { or Loss }\end{array}$ & \begin{tabular}{|c|} 
DGR/DLR Before \\
the \\
implementation
\end{tabular} & $\begin{array}{l}\text { DGR/DLR After } \\
\text { the } \\
\text { implementation }\end{array}$ & $\begin{array}{c}\text { DGR, DLR } \\
\text { Value }\end{array}$ \\
\hline \multirow{2}{*}{$\begin{array}{c}\text { 2011-01-01 } \\
\text { (First transfer } \\
\text { income tax } \\
\text { increase) }\end{array}$} & GR & 63 & 67 & 4 \\
\hline & LR & 9 & 9 & 0 \\
\hline \multirow{2}{*}{$\begin{array}{c}\text { 2012-01-01 } \\
\text { (Second transfer } \\
\text { income tax } \\
\text { increase) }\end{array}$} & GR & 51 & 21 & -30 \\
\hline & LR & 10 & 8 & -2 \\
\hline \multirow{2}{*}{$\begin{array}{l}\text { 2013-01-01 } \\
\text { (Second } \\
\text { acquisition tax } \\
\text { increase) }\end{array}$} & GR & 42 & 43 & 1 \\
\hline & LR & 11 & 9 & -2 \\
\hline \multirow{2}{*}{$\begin{array}{l}\text { 2013-07-01 } \\
\text { (Third } \\
\text { acquisition tax } \\
\text { increase) }\end{array}$} & GR & 57 & 37 & -20 \\
\hline & LR & 17 & 15 & -2 \\
\hline Statistical test & $\begin{array}{c}\text { GR } \\
\text { Chi square }\end{array}$ & $27.697^{\cdots}$ & $\begin{array}{c}\text { LR } \\
\text { Chi square }\end{array}$ & 4.616 \\
\hline
\end{tabular}

This study uses the 2,245 data through the certificate copy of the registration. The range of analysis is from the -60 days of tax increase implementation to the 60 days of tax increase implementation.

$* * *$ : Significant level is less than 0.01

**: Significant level is less than 0.05

*: Significant level is less than 0.1

Value: After tax policy implementation GR or GL - before tax policy implementation GR or GL.

It suggests that they did more realized gain and loss before the implementation more than before the increased tax rate. To find out the difference between the groups, this study used Kruskal-Walis analysis. They are significant, but not same. It means that the realized gain is raised after the first and third tax rate increase, while the realized gain is decreased after the second and fourth tax rate increase. The results were estimated due to the fact that the investors who made large profits more than 300 million won sold their property before the increase because of increasing tax rate policy to the group that transfer marginal profit was over 300milion. Also, investors expected the decrease of the real estate value because of the low demand and trading volume caused by the acquisition tax increase at the same time. 
Table 2 below is analysis on the realized gain and loss before increase acquisition tax and after the loss.

\subsection{Analysis of Frequency of Profit and Loss, According to Decreasing the Tax Rate}

The result of the analysis, DGR and DLR is calculated at 11 and 2 in the first transfer income tax, the realized gain and loss is raised after implementation of the decrease. However, DGR is -3 in the second transfer income tax decrease period, which means that the realized gain is larger. But, the realized loss is bigger after the implementation judging from the fact that the DLR is calculated at 1.

At first, the outcome after the first decrease of transfer income tax was caused by the selling of investors on the real estate after the tax reduction that recovered the expectation on market. In addition, investors did more realized gain for uncertainty of profit because there was a chance to have a loss during the global financial crisis. Meanwhile, the result of the second decline of transfer income tax increased the gain realization before the transfer income tax decline. Also, the loss realization increased after the transfer income tax decline. The investors who had gain showed more aggressive investment behavior because they thought it was a permanent increase. Investors with a loss tried a loss cut because they considered the decrease of transfer income tax as a chance of increase on the trading volume and the recovery of their loss.

Next, the result of analysis about acquisition tax stated that it was not proper to analyze the first acquisition tax rate due to the lack of data. Therefore, this study dealt with the data of the second acquisition tax rate decrease. After the second decrease of acquisition tax data, the realized gain decreased, but realized loss increased since the implementation. In the third tax decrease, different from the second tax decrease, realized gain increase more after the implementation of the decrease tax rate but realized loss was not changed. Both realized gain and the loss increased after the fourth acquisition tax rate implementation. The realized gains and loss decreased after the fifth decrease acquisition tax rate implementation.

The result of the second decrease tax rate was not big, but it made investors who had profit real estate to have a positive expectation so that they can realize profit quickly, and it made investors who had loss real estate to do a loss cut which is more close to a loss avoidance than the prior investment behavior. The big difference occurred in the profit real estate after the third acquisition tax increase.

It suggests that the synergy effect which came from a decrease of the acquisition tax and an improvement of DTI led to the increase of selling and demand of profit real estate. Fourth acquisition tax decrease was expected, but conducted in retard. In this situation, the investors of real estate waited because they wanted to increase the number of trading. For this reason, the realized profit and the loss real estate increased after the implementation.

In addition, the fifth acquisition tax decrease started to reduce permanently. So, the 
change or effect is insignificant because the investors learned from the frequently conducted policy even before the decrease implementation started.

Table 3 below shows analyzed data about the change of realized gain and loss of real estate according to the decrease of acquisition tax and the transfer income tax policy implementation.

Table 3: The analysis of DGR-DLR when the tax decreased

\begin{tabular}{|c|c|c|c|c|}
\hline $\begin{array}{l}\text { Implementation } \\
\text { of tax increase }\end{array}$ & \begin{tabular}{|c|c|}
$\begin{array}{c}\text { Separate Gain } \\
\text { or Loss }\end{array}$ & I \\
\end{tabular} & $\begin{array}{c}\text { DGR/DLR Before } \\
\text { the } \\
\text { implementation }\end{array}$ & $\begin{array}{l}\text { DGR/DLR After } \\
\text { the } \\
\text { implementation }\end{array}$ & $\begin{array}{l}\text { DGR, DLR } \\
\text { Value }\end{array}$ \\
\hline \multirow{2}{*}{$\begin{array}{c}\text { 2009-01-01 } \\
\text { (First transfer } \\
\text { income tax } \\
\text { decrease) }\end{array}$} & GR & 19 & 30 & 11 \\
\hline & LR & 2 & 4 & 2 \\
\hline \multirow{2}{*}{$\begin{array}{c}2010-01-01 \\
\text { (Second transfer } \\
\text { income tax } \\
\text { decrease) }\end{array}$} & GR & 37 & 34 & -3 \\
\hline & LR & 6 & 7 & 1 \\
\hline \multirow{2}{*}{$\begin{array}{c}\text { 2006-09-01 } \\
\quad \text { (First } \\
\text { acquisition tax } \\
\text { decrease) }\end{array}$} & GR & 1 & 1 & 0 \\
\hline & LR & 0 & 0 & 0 \\
\hline \multirow{2}{*}{$\begin{array}{c}\text { 2011-03-22 } \\
\text { (Second } \\
\text { acquisition tax } \\
\text { decrease) }\end{array}$} & GR & 72 & 70 & -2 \\
\hline & LR & 8 & 9 & 1 \\
\hline \multirow{2}{*}{$\begin{array}{l}\text { 2012-09-24 } \\
\text { (Third } \\
\text { acquisition tax } \\
\text { decrease) }\end{array}$} & GR & 33 & 53 & 20 \\
\hline & LR & 11 & 11 & 0 \\
\hline \multirow{2}{*}{$\begin{array}{l}\text { 2013-03-22 } \\
\text { (Fourth } \\
\text { acquisition tax } \\
\text { decrease) }\end{array}$} & GR & 49 & 66 & 17 \\
\hline & LR & 10 & 16 & 6 \\
\hline \multirow{2}{*}{$\begin{array}{c}\text { 2014-01-01 } \\
\quad \text { (Fifth } \\
\text { acquisition tax } \\
\text { decrease) }\end{array}$} & GR & 23 & 20 & -3 \\
\hline & LR & 7 & 3 & -4 \\
\hline Statistical test & $\begin{array}{c}\text { GR } \\
\text { Chi square }\end{array}$ & $161.684^{\cdots}$ & $\begin{array}{c}\text { LR } \\
\text { Chi square }\end{array}$ & $41.509^{\cdots}$ \\
\hline
\end{tabular}

This study uses the 2,245 data through the certificate copy of the registration. The range of analysis is from the -60 days of tax decrease implementation to the 60 days of tax decrease implementation.

***: Significant level is less than 0.01

**: Significant level is less than 0.05

*: Significant level is less than 0.1

Value: After tax policy implementation GR or GL - before tax policy implementation GR or GL 


\subsection{Analysis of PRMR and LRMR According to Increase Tax Rates}

The result of examining the psychology of real estate investors using PRMR of profit real estate and LRMR of loss real estate stated that the investors of real estate can earn a potential profit. Moreover, the LRMR increased more than before a tax rate increase in loss real estate, which implied that the investors sold it before they have a big loss.

These results show that after the increase of tax rate, investors' investment behavior would be more desirable. First, in a 6-month analysis, PRMR at the time of increasing of transfer income tax was calculated at 0.2. However, after the implementation, PRMR was 0.128 .

It suggests that after the increase, the investors showed more desirable investment behavior than before. It is because the investors who sold their property before tax rate increase did not get their potential profit because they reacted urgently to a negative signal such as increase tax rate.

Real estate investors also had a loss which was preventable because they reacted risk-averse to the negative signal. Next, the PRMR value before the increase is 0.246 , but PRMR after the increase is 0.134 during the period of increase of second transfer income tax analysis. It means that investors got more potential profit than before the increase because of the increase of acquisition tax and transfer income tax. As previously mentioned, it is because the investors sold their property urgently because they reacted to increase the tax rate negatively. And, after the increase, the investment behavior was more preferable than before because they trade it more carefully for incidence of taxation. These results rejected hypothesis 5-2.

Before the increase of transfer income tax, investors do not show a desirable investment behavior. However, they made more preferable investment behavior after the increase. Before the implementation of the second increase of acquisition tax in January 1, 2013, PRMR was 0.172. After the implementation, it was 0.142.

It confirmed that investors traded more carefully before the increase because the investors felt pressure from the increase of acquisition. Loss investors' LRMR raises from 0.005 to 0.006 during, before and after the increase. Potential loss would be bigger that is why investors traded more carefully.

It suggests that the increase of acquisition tax is influenced on the investors' careful trade. However, the increase in July 1, 2013, the third increase period, was different; PRMR (0.146) rises as 0.166 after the increase. It could be considered that the increase of acquisition tax in July 1, 2013 did not influence the investors because of the 8.28 plan which was announced in August 28, 2013. Unlike the previous increase policy, the third increase, which was temporal, made investors who had profit real estate sell their property quickly due to the uncertainty of policy which was shifting frequently. But, it was good for the investors who had loss real estate because they sold their property quickly to prevent a potential loss. It was interpreted that if the change of policy occurs often, investors sold their property quickly because of the 
anxiety.

The result accepts the hypothesis 5-1 in increase, but rejects it in the result of first and second transfer income tax increase and second acquisition tax increase. This result is similar to PRMR-LRMR which was an analysis of one year period, but there is a different outcome in third acquisition tax increase period analysis.

First of all, PRMR before the third acquisition tax increase was 0.225 . But, after the increase, PRMR was 0.117 . It was averse the six-month analysis.

In addition, hypothesis 5.1 is rejected because LRMR goes up from 0.009 to 0.018 after the increase. The reason of the difference between one-year analysis and sixmonth analysis is because of the permanent reductions of acquisition tax that was implemented in the 8.28 plan after the increase. This permanent reduction system was fixed in January 2014 and it made trade safer than before. Therefore, one-year analysis is more stable than the six-month analysis, which helps investors' potential profit to decrease.

\section{Discussions and Conclusion}

This study examined the cognitive bias of real estate investors using DGR-DLR model and investigated how the change of government's tax policy could influence cognitive bias of investors. The DGR-DLR model, which is a frequency model are used for the potential profit and the loss rate.

The results of the study were rejected in the first and second increase of transfer income tax and a second increase of acquisition tax. This study has investigated the real estate investor's cognitive bias and the influence of change of tax policy using 2,245 copies of residence register to solve the data collection problem. Previous researches showed no case of using PRMR and LRMR in the real estate market except the stock market. So, this study is different from the former studies of real estate investment behavior.

It explains whether the investment behavior is appropriate using PRMR and LRMR. In addition, there are academic suggestions : it expends the base of behavior taxation investigate to import the concept of the investment psychology, and it studies the cognitive bias in the real estate market and finds the influences on recency prejudice. And then there is a social suggestion that cognitive bias could be reduced by using the investment psychology if the tax rate increases as a government tax policy. If the recency prejudice is used, the extended effect will be better.

The investigation used monthly real estate price of each residence in calculating PRMR and LRMR value.

It solves the problem that there no daily trading in real estate. Although this real estate price could confirm the change of each residence, it is difficult to explain the price change, and it has a limit on the possibility of attenuating data. But the explanatory power is as good as a substitute because there is no daily index of real estate. This limitation should be improved through further research. 


\section{Acknowledgment}

"Funding for this paper was provided by Catholic University of Daegu"

\section{References}

Ahmed, F., Uddin M. R., and Mahammad S. R. (2013). Future of Real Estate Business (Ready-made Flat) in Khulna City. International Journal of Scientific and Research Publications, 3(12), 435.

Biswas, B. K. (2015). Price of Building Materials and Land Value and its Effect on Individual House Ownership of Middle-Income People. from Khulna University.

Collins, Julie H., and Kemsley, Deen, (2000). Capital Gains and Dividend Taxes in Firm Valuation: Evidence of Triple Taxation. Accounting Review. 75(4), 405-427.

Dai. Zhonglan, Maydew Edward, Shackelford Douglas A., Zhang, and Harold H. (2008). Capital Gains Taxes and Asset Prices: Capitalization or Lock-in? \& quot. The Journal of Finance. 63(2), 709-742.

Elffers, Henk, Henry SJ Robben, Dick J. Hessing, and quot. (1992). On measuring tax evasion.\& quot. Journal of economic psychology, 13(4), 545-567.

Engelhardt, Gary V., and quot. (2003) Nominal loss aversion, housing equity constraints, and household mobility: evidence from the United States.\& quot. Journal of Urban Economics, 53(1), 171-195.

Kahle, Jennifer B., and Richard A. White. (2004). Tax professional decision biases: The effects of initial beliefs and client preference. Journal of the American Taxation Association, 26(s-1), 1-29.

Odean, Terrance. (2003). Are individual investors tax savvy? Evidence from retail and discount brokerage counts. Journal of Public Economics, 88, 419-442.

Seong-hoon Jeong, and In-ho Choi. (2019). Empirical analysis of Cognitive bias in Behavioral Finance Model, World Journal of Accounting, Finance and Engineering, 3(1), 7-8.

Talpsepp, Tõnn. (2011). Reverse disposition effect of foreign investors. Journal of Behavioral Finance, 12(4), 183-200.

Thaler, Richard H. (1999). Mental accounting matters. Journal of Behavioral decision making, 12(3), 183-206.

Walsh, Keith. (2013). Understanding takppayer behavior-new opportunities for tax administration. The Economic and Social Review, 43(3), 451-475. 